\title{
Research Paper \\ Effects of Group Counseling Based on Logo Therapy to Decrease Loneliness in Elderly Men
}

\author{
Negin Yazdanbakhsh ${ }^{1}$, Seyed Jalal Younesi ${ }^{1}$, Soraya Aazimiyan ${ }^{1},{ }^{*}$ Mahshid Foroughan ${ }^{2}$
}

1. Department of Counseling, University of Social Welfare and Rehabilitation Sciences, Tehran, Iran.

2. Iranian Research Center on Ageing, University of Social Welfare and Rehabilitation Sciences, Tehran, Iran.

Citat On: Yazdanbakhsh N, Younesi J, Aazimiyan S, Foroughan M. [Effects of Group Counseling Based on Logo Therapy to Decrease Loneliness in Elderly Men (Persian)]. Iranian Journal of Ageing. 2016; 11(3):392-399. http://dx.doi.org/10.21859/sija-1103392

: http://dx.doi.org/10.21859/sija-1103392

Received: 14 Mar. 2016 Accepted: 18 Jul. 2016

Key words: Loneliness, Ageing, Group counseling, Logo therapy

\section{A B S T R A C T}

Objectives The elderly are an increasing social group in the present society which has gained importance in the age pyramid of our country. The present study aimed to examine the effects of group counseling based on "logo-therapy" as a method of rehabilitation to reduce loneliness in elderly men.

Methods \& Materials This was a quasi-experimental study with pretest posttest and control group. Thirtysix elderly men from Jahandidegan center in Tehran were selected for our study by sampling. They were randomly divided into two groups; experimental and control. Each group consisted of 18 men. Group logo therapy was applied to the experimental group for eight 90-minute sessions, once a week. Followup test was conducted one month after the test. We used the Dehshiri et al. Loneliness questionnaire (2008) to assess the level of loneliness.

Results Using analysis of covariance, our findings showed that group counseling based on logo therapy had meaningful and positive effect on decreasing loneliness of elderly male in the experimental groups $(\mathrm{P}<0.003)$

Conclusion Group counseling based on logo therapy was found to decrease loneliness scores of elderly men. Therefore, the approach taken in this study can be considered as an appropriate method for psychological interventions in elderly men. 


\title{
اثربخشى مشاوره تَروهى با رويكرد معنادرمانى بر كاهش احساس تنهايى مردان سالمند
}

\author{
نكين يزدانبخش''، سيدجلال يونسى'، ثريا عظيميان'، "مهشيد فروغان' \\ ا. ا. كروه مشاوره، دانشكاه علوم بهزيستى و توانبخشي، تهران، ايران.

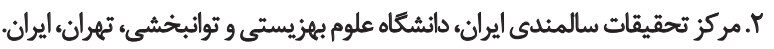

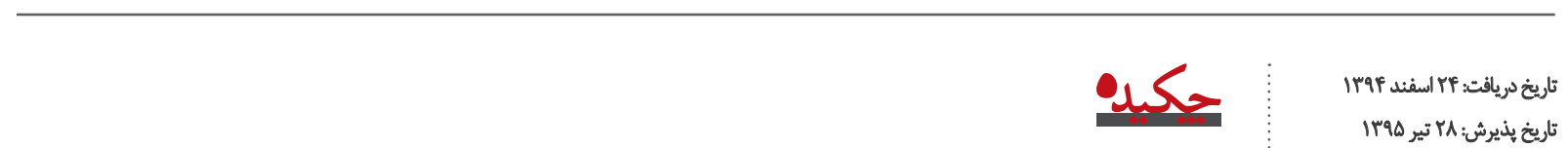









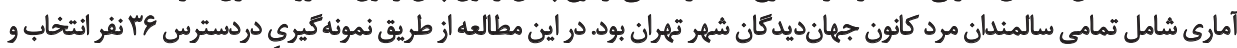

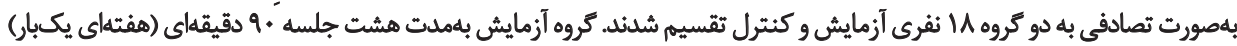

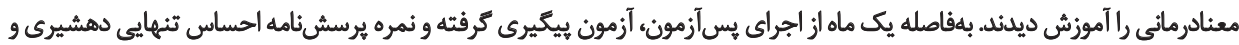
همكاران قبل و بعداز مداخله مقايسه شئد

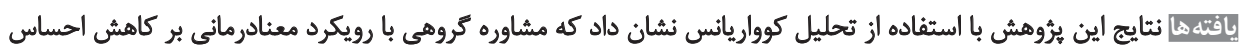

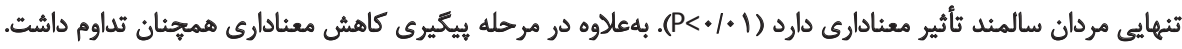

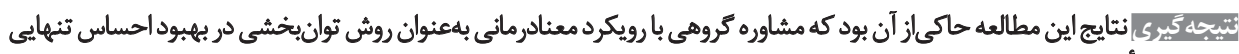

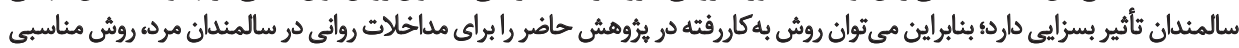

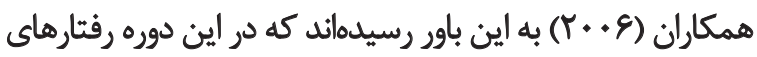



doses

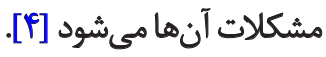

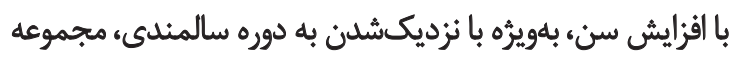

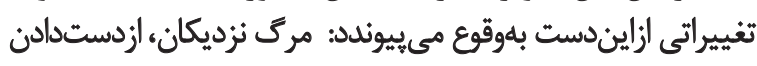

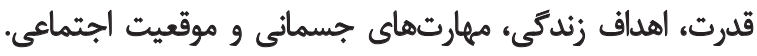

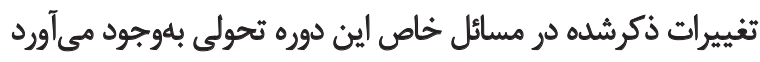

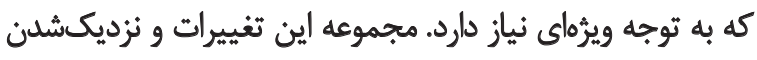

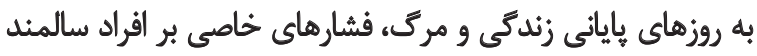

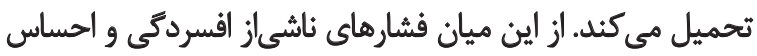

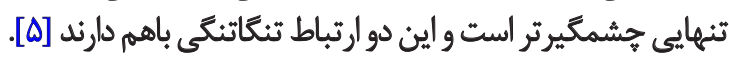

احساس تنهايى يكى از نشانههاى افسردگى و عامل ايجاد

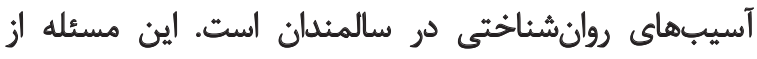



جهان در سايه بيشرفتهاى علمى شاهد افزايش جمعيت

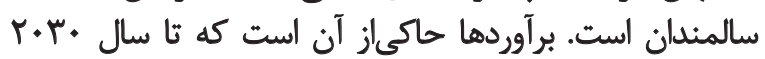

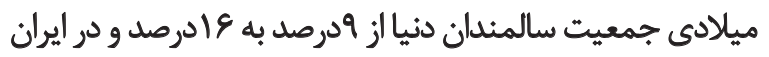



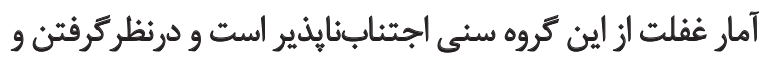





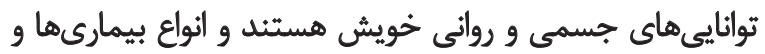

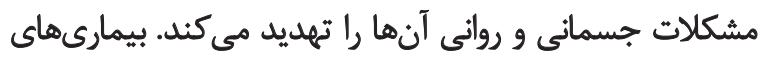

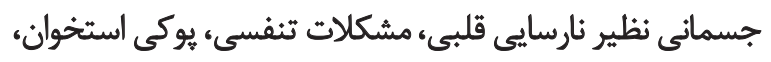

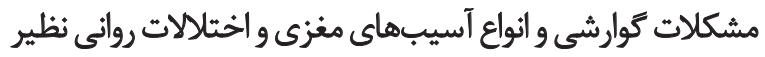



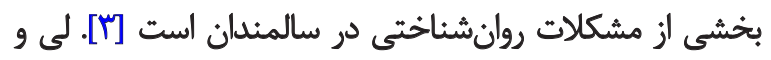


درزمينه اثربخشى معنادرمانى بر اففردگى سالمندان انجام دادي.

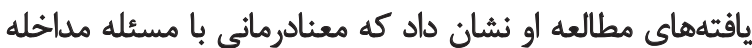



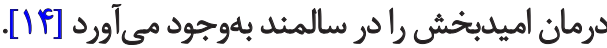

داشتن معنا در زندگى در افزايش سلامت روانى انسان و بهيبود

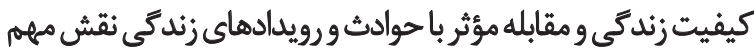

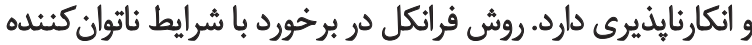

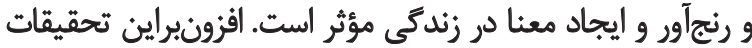

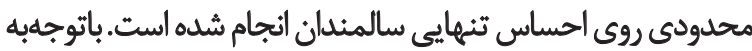

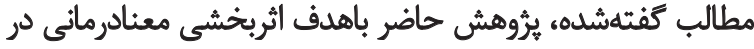



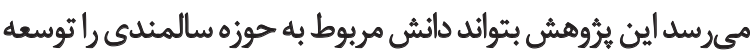
دهد و معنادرمانى با فنون خاص بله اين افراد كمك مؤثرى كند.

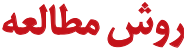

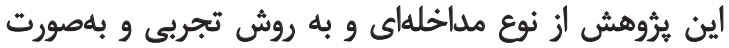

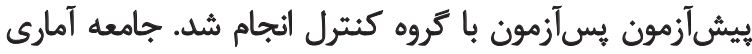

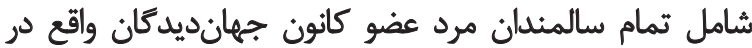

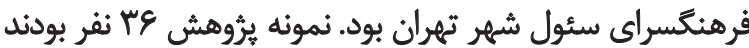

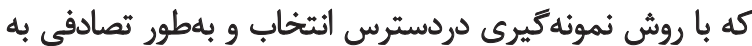

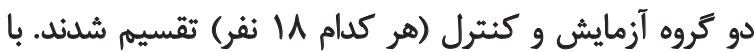

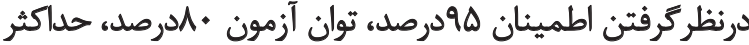





$$
\text { نفرى در هر كروه لازم بود. }
$$

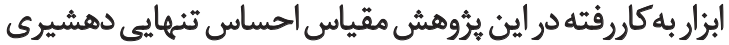

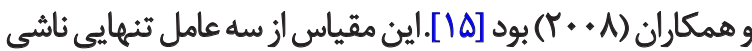

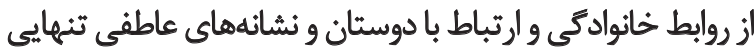

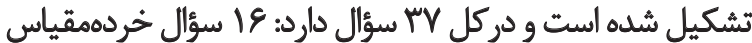

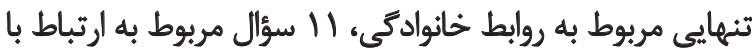



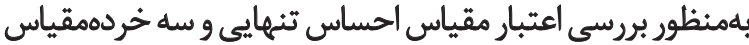



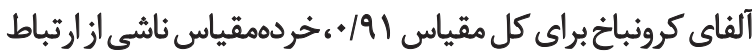

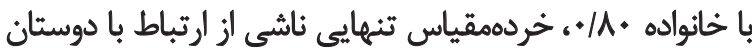

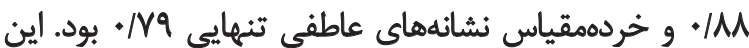

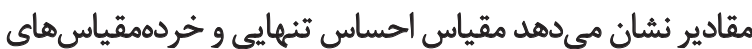

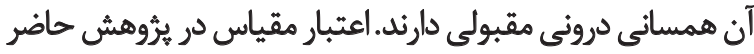

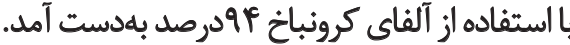

ملاكهاى ورود سالمندان در اين يروهش از اين قرار بودي: 1.

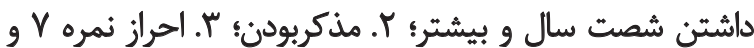

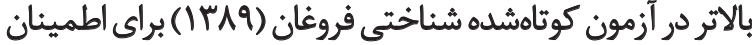

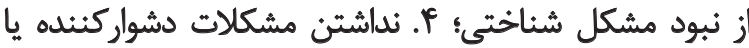

ازدست دادن نزديكان و كمرنكش تشن ارتباطات تجربه مي شود [9].



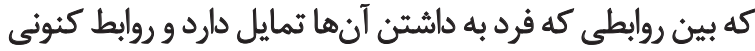

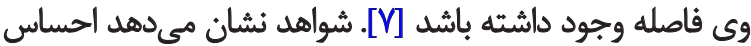



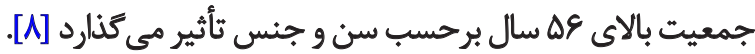
براى كاهش مشكلات روانى سالمندان درزمينه بهداشت

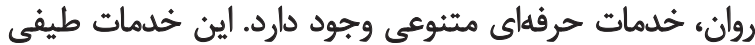

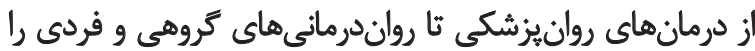

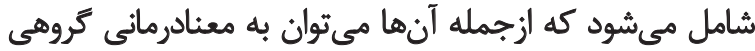



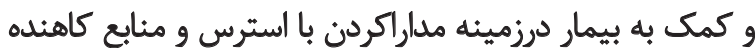

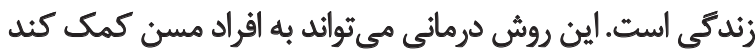





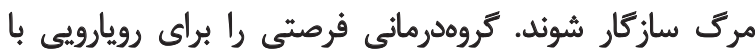

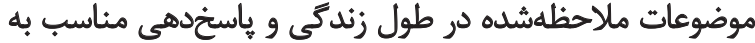

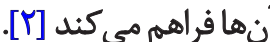

معنادرمانى ازجمله روش هاى درمانى مؤثر بهشمار مي آيد كه در



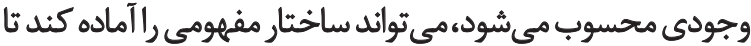

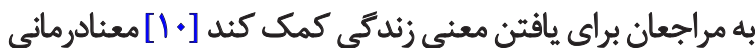

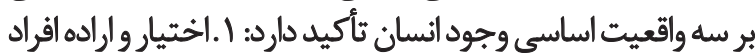

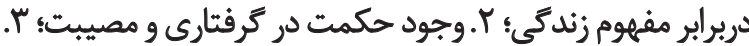

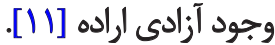

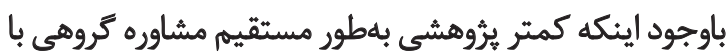

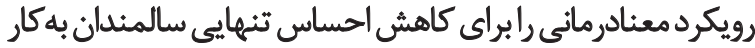

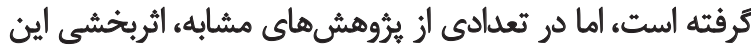

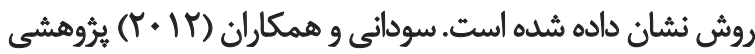

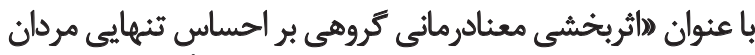

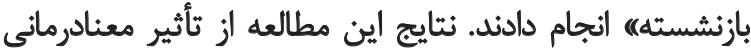

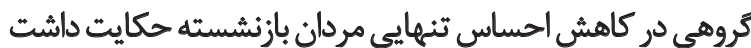

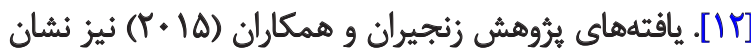

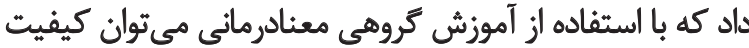

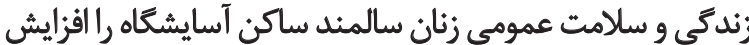







در تحقيقات خارجى هم اثربخشى اين روش نشان داده شده

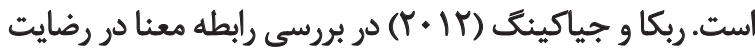

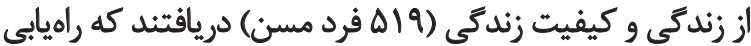



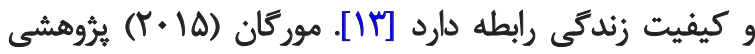




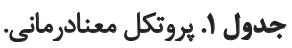

\begin{tabular}{|c|c|}
\hline تعيين هدف و ثوانين كروه، آشنائى اعضاى كروه بـا يكديكر، مشاوره و بحث درباره شرايط سالمثدى (احساس تنهايى) و ارائه مثشور تروه و قراردا & 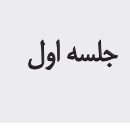 \\
\hline معنايابى و كرفن معنا از بافت تاريخحى زندكى و مسئوليتيذيرى & جلسه دوم \\
\hline تغيير نكرش ها و كرفتن معنا از طريق راههاى كشف و كرفتن معنا از خلق ارزش ها و مسئوليت & جلسه سوم \\
\hline كرفتن معنا از ميان تجربه ارزش ها و كرفتن معنا أز آرزوها و اميدها & جلسه جيارم \\
\hline هناي مرك، زندكى، أزادى و مسثوليت & جلسه ينجم \\
\hline هسئوليت، خودجمايتى، علاقه اجتماعى و غُلبه بر يأس & جلسه شششم \\
\hline حمايت عاطفى اعضا از يكديكر، تكميل جملههاى ناثمام براى تعامل اعضا، حمايت عاطفى اعضا از يكديكر و تشويق آنان براى درخواست حمايت & جلسه هفتم \\
\hline خلاصه و جمعبندى و اتمام جلسات و صحبت اعضا درباره آموختههايشان در كروه & جلسه هشتم \\
\hline
\end{tabular}

L

اين زمينه همكار بروهشكر باشند.

سيس به كروه آزمايش هشت جلسه مشاوره كروهى با بارويكرد

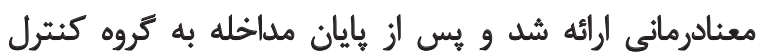

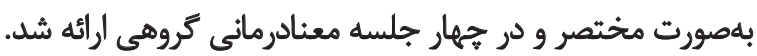

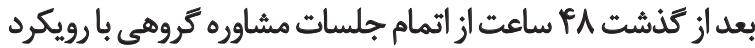

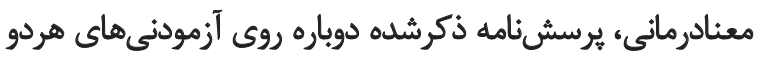











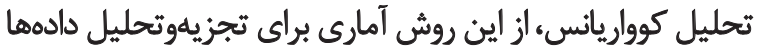

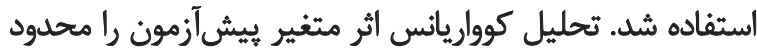





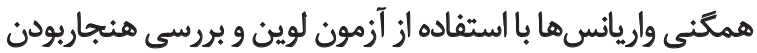

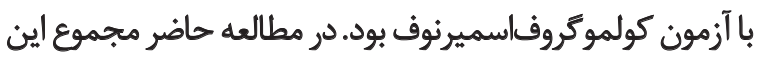
يبيش فرض ها برن كوركى و ثأييد شد.

يافتهاهنا

كروه نمونه شامل ع آنفر از سالمندان مرد بود كه ل1 انفر در تروه

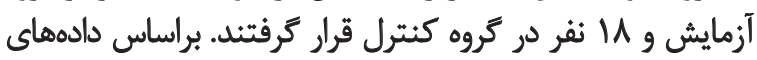

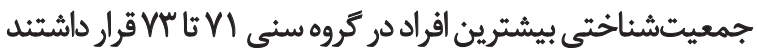

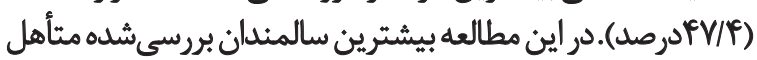

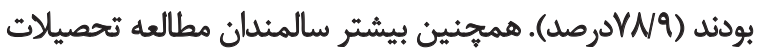



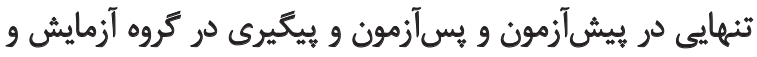

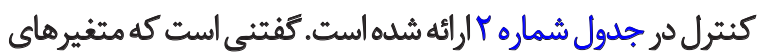

ناممكنكننده ارتباط مانند اختلال تكلم يا مشكل شنوائي

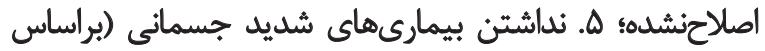



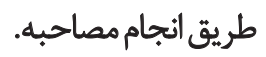

ملاحظات اخلاقى اين مطالعه موضوعات زير رادربرداشت:

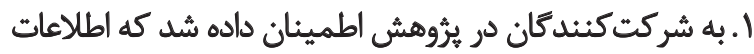

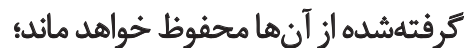

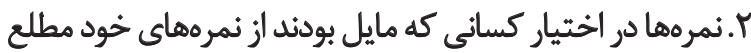
شوند، قرار كرفت؛ r. براى جلسات مشاوره كروهى برنامهريزى مناسبى انجام شدي؛

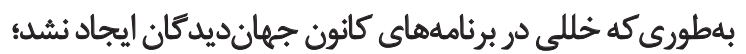

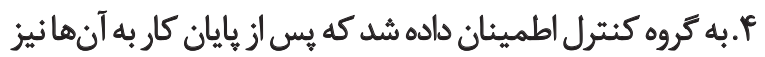

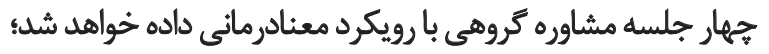
ه. هرفرد در هرزمان از انجام يُّوهش كه مايل بوداد، مي توانست

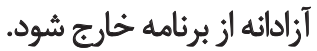

$$
\text { روش مداخله }
$$

جلسات كروهى بهصورت هشت جلسه نوددقيقهاى (هفتهاى

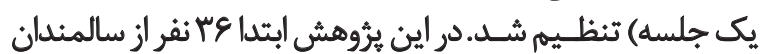

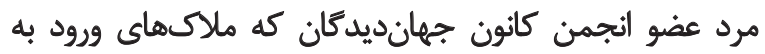

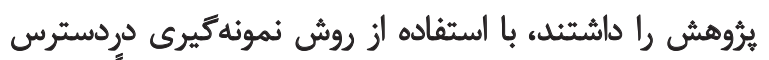

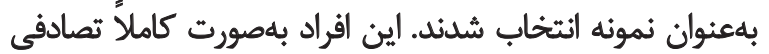

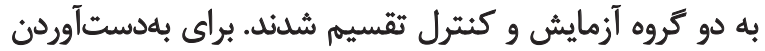





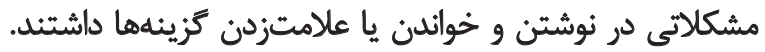
براى رفع اين مشكل از مراقبان و كارمندان كانون تقاضا شاند كهد در 


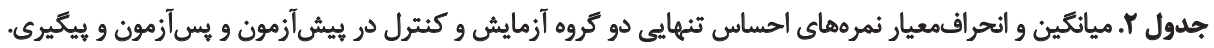

\begin{tabular}{|c|c|c|c|c|c|}
\hline ييكيرى & يس آزمون & ييش آزمون & \multirow{2}{*}{ تعداد } & \multirow{2}{*}{$\Delta$} & \multirow{2}{*}{ متغير } \\
\hline مياتكين (انحرافمعيار) & مياتكين (انحرافمعيار) & مياتكين (انحرافمعيار) & & & \\
\hline $\mid V / \cdot \cdot\left(1 \cdot / p^{2} \mid\right)$ & IEAT(E|\&E) & $\pi r / 9 Y(q / \% q)$ & M & آلزمايش & \\
\hline$T / / \Delta \Delta(Q / T \Delta)$ & $M I / I \Delta(q / P H)$ & $\mathrm{rm} / \cdot \cdot(\mathrm{q} / \mathrm{r} \mathrm{A})$ & $M$ & كنتل & احساس تنهائي \\
\hline IQTV(Q/AY) & $M / \circ \&(N \cdot \Delta)$ & $\pi / U(\Psi / T \Lambda)$ & re & كل & \\
\hline$r / \backslash Q(\cdot / T q)$ & $r / \cdot N(\cdot / M)$ & $r / E V(\cdot / \Delta A)$ & $M$ & أزمايش & \\
\hline$r / \& r(\cdot / R T)$ & $r / \Lambda \cdot(\cdot / r \Delta)$ & $r / 9 Y(\cdot / \Delta \cdot)$ & $M$ & كتثرل & ارئباط با خانواده \\
\hline$r / T N(* / F)$ & $r / H Y(\cdot / M T)$ & $r / V q(\cdot / \Delta F)$ & re & كل & \\
\hline$V / F T(+/ m q)$ & $1 / 4+(+/ r q)$ & $1 / \Delta \Delta(+/ F q)$ & $M$ & أزمايش & \\
\hline$V / 8)(+/ F \Delta)$ & $1 / \Delta q(+/ A Y)$ & $V / \Delta A(+/ T A)$ & $M$ & كتترل & ارتباط با دوستان \\
\hline$V / \Delta H(+/ R T)$ & $V / \Delta r(+/ F I)$ & $V / \Delta \&(+/ F Y)$ & re & كل & \\
\hline $1 / 89(+/ r q)$ & $1 / 8 \cdot(+/ M Y)$ & V/AY $(+/ T Y)$ & $M$ & 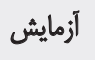 & \\
\hline$T / \backslash \Delta(\cdot / P \Delta)$ & $T / \cdot R(\cdot / F)$ & $r / \cdot \Delta(\cdot / P V)$ & M & كتيرل & نشائهاي عاطفى \\
\hline V/ar(*/Pr) & $V / A r(\cdot / M I)$ & 1/99(•/ศ๑) & re & كل & \\
\hline
\end{tabular}

$\stackrel{0}{2}$

جدول ب. نتايج تحليل كوواريانس مقايسه نمرهماى بسآزمون كروه آزمايش با تروه كنترل بر احساس تنهايى.

\begin{tabular}{|c|c|c|c|c|c|c|c|c|}
\hline توان آمارى & اندازه اثر & Sig. & $F$ & مجذور مياتكين & درجه آزادى & مجموع مجذورات & منيع تغييرات & متغير \\
\hline.$/ \mu$ & ק & $\cdot|r|$ & WG. & geray & 1 & se/ar & ييش آزمون & \\
\hline
\end{tabular}

. laT . IAT

احساس تنهايى



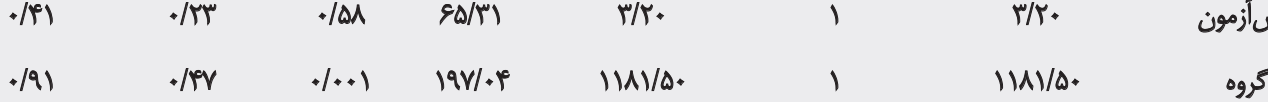

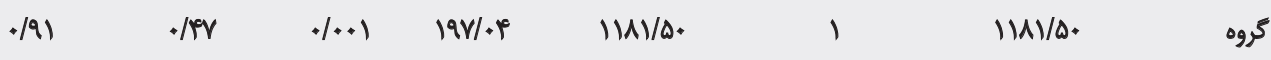

ارتباط باخانواده

\begin{tabular}{|c|c|c|c|c|c|c|c|c|}
\hline & & & & & ra & $19 W N .$. & كل & \\
\hline . & $\cdot|M|$ & $\cdot M$ & $\Delta F / / T$ &.$/ M$ & 1 &.$/ M$ & ييش أزمون & \\
\hline \multirow[t]{3}{*}{.$M$} & $.1 \% \Delta$ & $. \cdot . r$ & WWFE & IAVE/TA & 1 & IOVE/TA & كروه & \\
\hline & & & & glar & ه & $1 \Delta S / N^{C}$ & خطا & \\
\hline & & & & & rA & EXAVl.. & كل & \\
\hline
\end{tabular}

\begin{tabular}{|c|c|c|c|c|c|c|c|c|}
\hline.$/ p$. & . / $\Delta \Delta$ & $\cdot 109$ & $\Delta V / \pi \varphi$ & $1 / \Delta 9$ & 1 & $1 / 09$ & يش آزمون & \\
\hline \multirow[t]{3}{*}{.$/ 9}$. & $\cdot / r V$ & $1 . \pi$ & $1 . \Delta / 91$ & $811 / 91$ & 1 & $811 / P A$ & كروه & شانههاى \\
\hline & & & & $r / \varphi_{0}$ & ه & $11 . / 49$ & خطا & عاطفى \\
\hline & & & & & ra & $\mid r q .4 / *$. & كل & \\
\hline
\end{tabular}


برّوهش ديكرى مور كان اثربخشى معنادرمانى بر افسردگى سالمندان

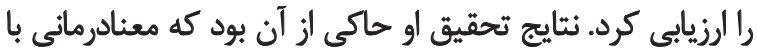

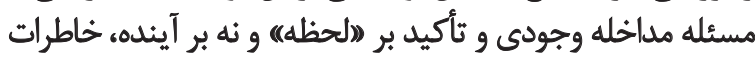
شاد و زمينه درمان اميدبخش راد وادر سالمند ايجاد ميكند. در تبيين يافتهائ ذكرشده در تأثير معنادرمانى كروهي بر

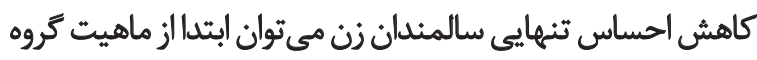

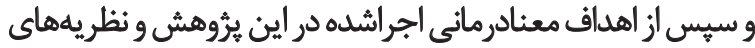

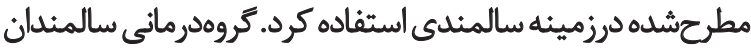

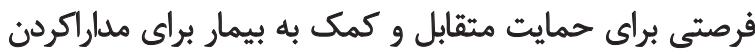

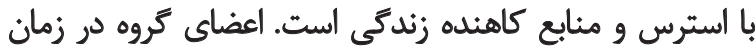

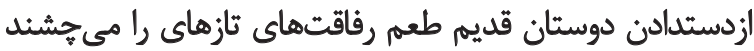

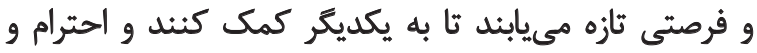

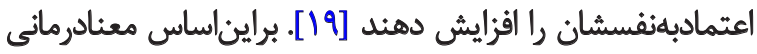

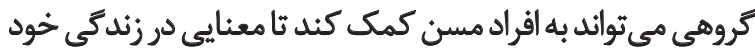

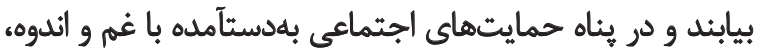



درزمينه سالمندى ديدكاههاى متعددى براى تبيين اثربخشى

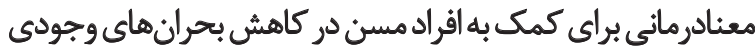

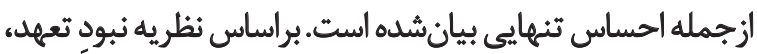



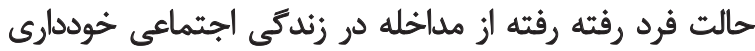

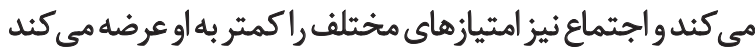

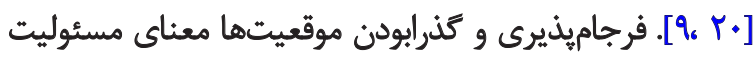

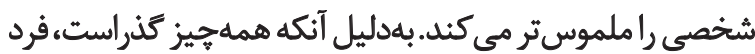

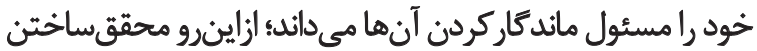

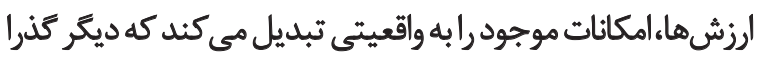



برايناساس مسئوليت نقش مهمي در تجربهكردن معنا دارد؛



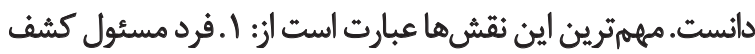

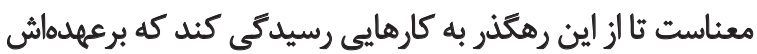

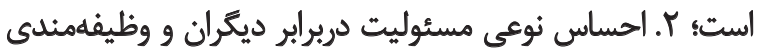

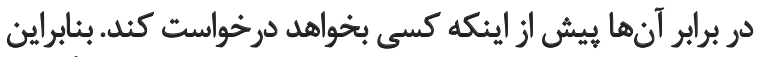

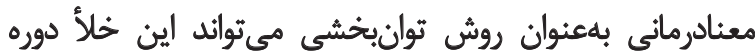

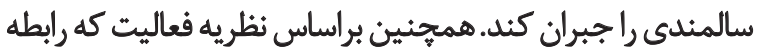

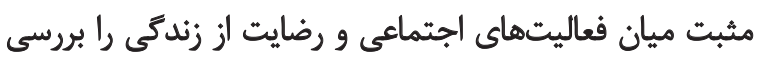

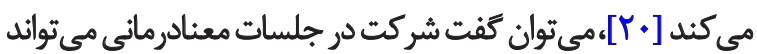



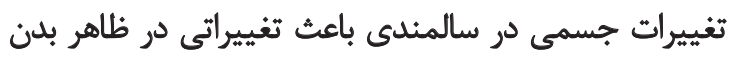

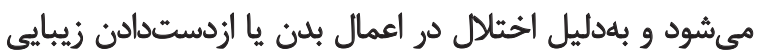

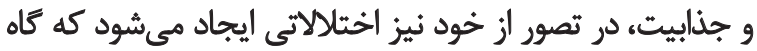

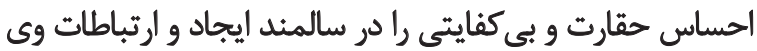



جمعيتشناختى و احساس تنهايي قبل از مداخله بهترتيب با بارئ

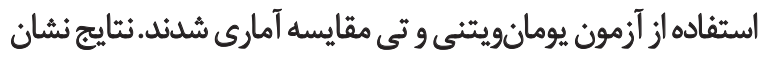


و واحساس تنهايى تفاوت معنادارى وجود نداشت إنظئ

در جدول شماره Y ميانكين و انحراف استاندارد دو كروه آزمايش

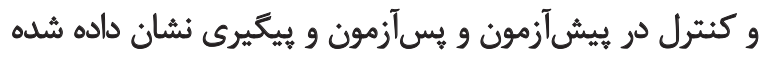

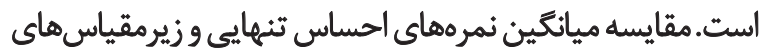

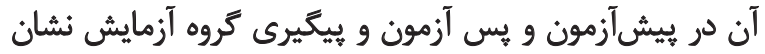

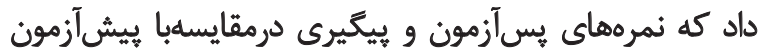





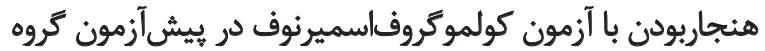

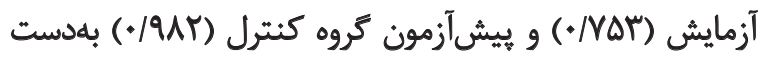

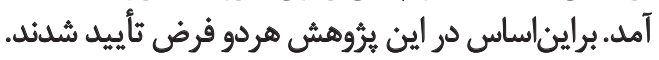
همانطوركه در جدول شماره r ملاحظه ميشود، اثر كروه يا

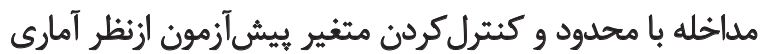

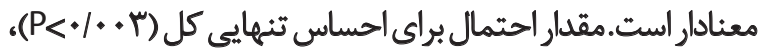

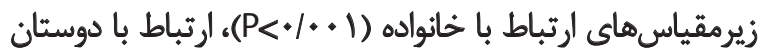



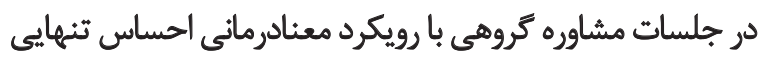
سالمندان را بهطور معنادارى كاهش داد ماد. در مرحله بهاديكيرى نيز

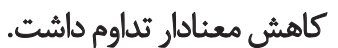

$\stackrel{\leftrightarrow}{*}$

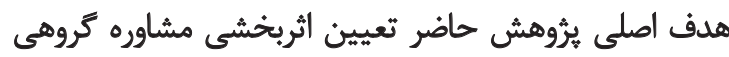

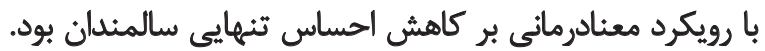

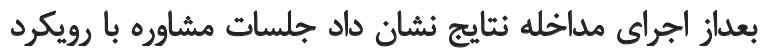

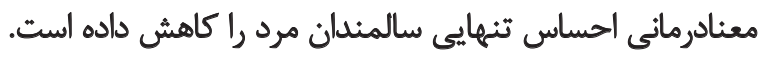

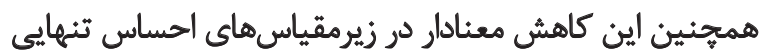



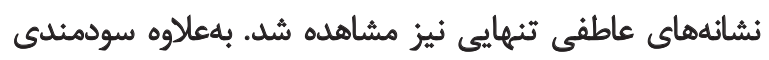

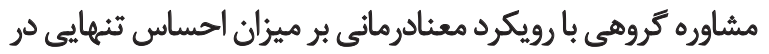
مرحله بيكيرى همجينان تداوم داشت.

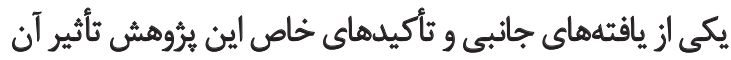

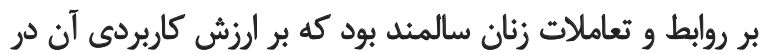

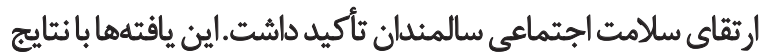

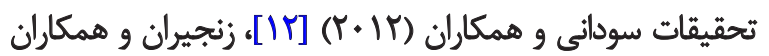

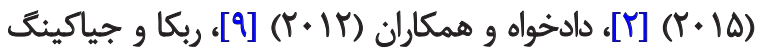

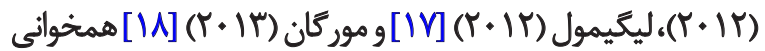





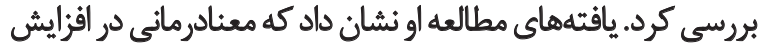

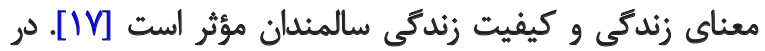


براى بيشكيرى يا كاهش مشكلات سلامت روان ازجمله افسردگى،

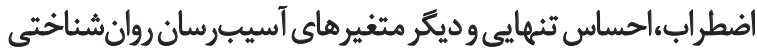
با تأكيد بر مشاوره كروهى با رويكرد معنادرمانى استفاده كرد.

$$
\text { تشيكر وقبدردائى }
$$

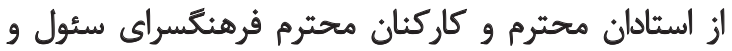

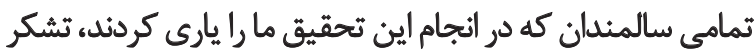



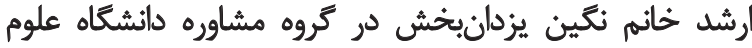
بهزيستى و توانبخشى تهران مي بياشد.
براي دستيابى به آن براى برانكيختن حس شهامت وخيرخواهي،

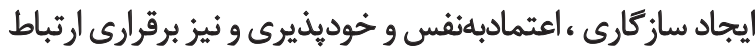

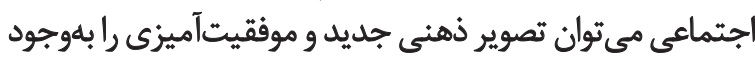

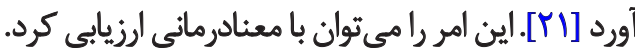
درزمينه مراجعان سالمندمى توان از شيوههايي مانند كَفتوكوى

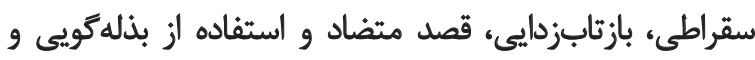

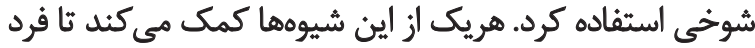

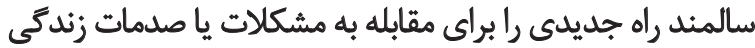

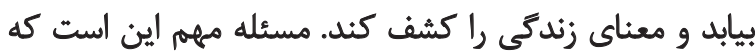

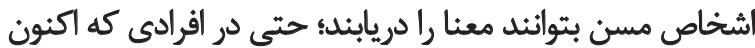



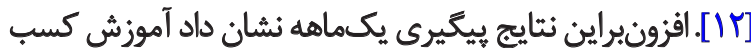

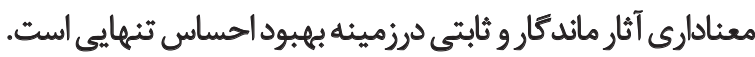



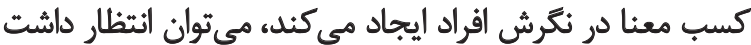

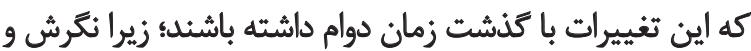

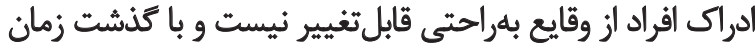
دستخوش تغيير نخواهد شد.

\section{نتيجلكيرى نيهايي}

دريايان مى توان نتيجه كرفت مداخلات و شيوههاى معنادرمانى

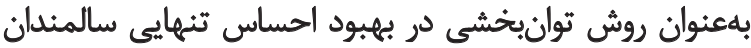



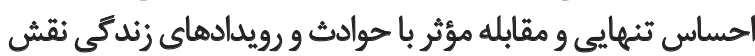







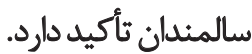

Letogutos

مبهمترين محدوديتهاى اين ثيروهش نمونه كيرى دردسترس

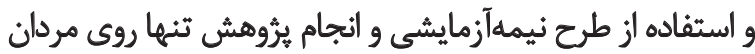



يشينهادها





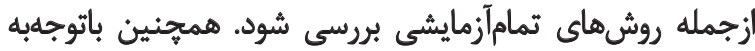



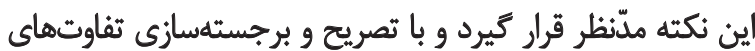





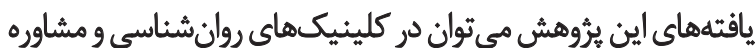




\section{References}

[1] Amini Rastabi Z, Sharifi AA, Refahi J. [Psychometric properties of geriatric depression scale in an Iranian sample (Persian)]. Iranian Journal of Ageing. 2013; 8(2):54-59.

[2] Zanjiran S, Borjali A, Kraskian A. [Effect of group Logotherapy education on quality of life and general health in women of sanatorium (Persian)]. Razi Journal of Medical Sciences. 2015; 21(127):39-51.

[3] Hweidi IM, Al-Obeisat SM. Jordanian nursing students' attitudes toward the elderly. Nurse Education Today. 2006; 26(1):23-30. doi: 10.1016/j.nedt.2005.06.003

[4] Lee TW, Ko IS, Lee KJ. Health promotion behaviors and quality of life among community-dwelling elderly in Korea: A crosssectional survey. International Journal of Nursing Studies. 2006; 43(3):293-300. doi: 10.1016/j.ijnurstu.2005.06.009

[5] Sheibani TF, Pakdaman S, Hassanzadeh TM. [The effect of reminiscence on depression and loneliness in elderly (Persian)]. Applied Psychology. 2010; 4(1):26-39.

[6] Sheibani Tazraji F, Pakdaman S, Dadkhah A, Hasanzadeh Tavakoli MR. [The effect of music therapy on depression and loneliness in old people (Persian)]. Iranian Journal of Ageing. 2010; 5(2):54-60.

[7] de Jong Gierveld J, van Tilburg TG. Social isolation and loneliness. In: Friedman HS, editor. Encyclopedia of Mental Health. $2^{\text {nd }}$ ed. Oxford: Academic Press; 2016.

[8] Hacihasanoğlu R, Yildirim A, Karakurt P. Loneliness in elderly individuals, level of dependence in activities of daily living (ADL) and influential factors. Archives of Gerontology \& Geriatrics. 2012; 54(1):61-66. doi: 10.1016/j.archger.2011.03.011

[9] Asghari N, Ali Akbari M, Dadkhah A. [The effects of group logotherapy on decreasing the degree of depression in female olds (Persian)]. Middle Eastern Journal of Disability Studies. 2012; 2(1):31-38

[10] Yalom I, Leszcz M. The theory and practice of group psychotherapy. New York: Basic Books; 2005.

[11] Mohammadi F, Dokanei Fard F, Heidari H. Effectiveness of logo therapy in hope of life in the women depression. ProcediaSocial \& Behavioral Sciences. 2014; 159(23):643-46. doi: 10.1016/j. sbspro.2014.12.440

[12] Sodani M, Shogaeyan M, Neysi A. [The effect of group logotherapy on loneliness in retired men (Persian)]. Researches of Cognitive \& Behavioral Sciences. 2012; 2(1):43-54.

[13] Rebecca P, Jiaqing O. Association between caregiving, 50 in an Asian sample: age as a moderator. Journal of Social Indicators Research. 2012; 108(3):525-34. doi: 10.1007/s11205-011-9891-9

[14] Morgan JH. What to do when there is nothing to do: the psychotherapeutic value of meaning therapy in the treatment of late life depression. Health, Culture \& Society. 2013; 5(1):324-30. doi: 10.5195/hcs.2013.126

[15] Dehshiri G, Borjali A, Sheykhi M, Habibi Askarabadi M. [Construction and validation of a scale loneliness among students (Persian)]. Journal of Psychology. 2008; 12(3):282-96.

[16] Garfami H, Shafiabadi A, Sanai Zaker B. [Effectiveness of group logo therapy in reducing symptoms of mental health problems in women Breast cancer (Persian)]. Journal of Psychiatry and Clinical Psychology. 2009; 4(13):35-42.

[17] Ligimol J. The effect of logotherapy on meaning and quality of life of the elderly in old age homes [MA thesis]. Karnataka: Christ University; 2012

[18] Morgan JH. Late-life depression and the counseling agenda: exploring geriatric logotherapy as a treatment modality. International Journal of Psychological Research. 2013; 6(1):94-101. doi: $10.21500 / 20112084.708$

[19] Fakhar F, Navabinezhad S, Foroughan M. [The role of group counseling with logo-therapeutic approach on the mental health of older women (Persian)]. Iranian Journal of Ageing. 2008; 3(1):58-67.

[20] Ghodrati S. [The Effect of group therapy on the basis of frankl theory on general health improvement in patients with multiple sclerosis (Persian)] [MA thesis]. Tehran: Allame Tabataba'i University; 2010.

[21] Franklin LL, Ternestedt BM, Nordenfelt L. Views on dignity of elderly nursing home residents. Nursing Ethics. 2006; 13(2):13046. doi: 10.1191/0969733006ne851oa 